\title{
A Avaliação da Educação Básica: do ranqueamento ao ensino e aprendizagem
}

\author{
Evaluation of Basic Education: \\ from ranking to teaching and learning
}

Evaluación de la Educación Básica:

desde el ranking hasta la enseñanza y el aprendizaje

MARLENE ZWIEREWICZ*

Universidade Alto Vale do Rio do Peixe, Caçador- SC, Brasil.

EZEQUIEL THEODORO DA SILVA**

Universidade Estadual de Campinas, Campinas- SP, Brasil

LUDIMAR PEGORARO***

Universidade Alto Vale do Rio do Peixe, Caçador- SC, Brasil.

VERA LÚCIA DE SOUZA E SILVA****

Universidade Alto Vale do Rio do Peixe, Caçador- SC, Brasil.

RESUMO: Partindo da constatação de que a avaliação externa em

larga escala tem priorizado o ranqueamento das escolas, esta pesquisa

* Doutora em Psicologia pela Universidade Federal de Santa Catarina e Doutora em Educação pela Universidade de Jaén, Espanha. É coordenadora, professora e pesquisadora do Programa de Mestrado Profissional em Educação Básica e Coordenadora do Curso de Pedagogia a Distância da Universidade Alto Vale do Rio do Peixe. E-mail: <marlenezwie@yahoo.com.br>.

** Doutor em Educação pela Pontifícia Universidade Católica de São Paulo e Livre Docência em Metodologia de Ensino pela Faculdade de Educação da Unicamp. Atua como professor no programa de Mestrado Interdisciplinar em Desenvolvimento e Sociedade da Universidade Alto Vale do Rio do Peixe. E-mail: <silvasilva1948@gmail.com>.

*** Doutor em Educação pela Universidade Federal do Rio Grande do Sul. Atualmente é professor e pesquisador na Universidade Alto Vale do Rio do Peixe e Docente dos Programas de Mestrados Acadêmico em Desenvolvimento e Sociedade (Interdisciplinar) e Mestrado Profissional em Educação Básica. E-mail: <pegoraro1963@hotmail.com>.

**** Mestre em Educação pela Universidade Regional de Blumenau e Doutora em Engenharia de Produção pela Universidade Federal de Santa Catarina. Atualmente é professora colaboradora no Mestrado Profissional em Educação Básica na Universidade Alto Vale do Rio do Peixe. E-mail: $<$ veraluciabalneario@gmail.com>. 
analisa os resultados desse processo junto às redes de ensino da $10^{\underline{a}}$ ADR de Caçador e, também, a percepção de docentes sobre os seus reais efeitos nos planejamentos. Utilizando pesquisas exploratória e documental e abordagens qualitativa e quantitativa, o estudo apontou que, apesar de os docentes conhecerem os resultados do ciclo avaliativo, a maioria desconhece os descritores e outras implicações subjacentes à avaliação em larga escala.

Palavras-chave: Educação básica. Avaliação. Planejamento.

ABSTRACT: Based on the fact that the large-scale external evaluation has prioritized the ranking of schools, this research analyzes the results of this process with the educational networks of the 10 th Regional Development Agency (ADC) of Caçador and also the teachers perception about its real effect in planning. Using exploratory and documentary research and qualitative and quantitative approaches, the study found that while teachers know the results of the assessment cycle, the majority was unaware of the descriptors and other implications underlying large-scale assessment.

Keywords: Basic education. Evaluation. Planning.

RESUMEN: Con base en el hecho de que la evaluación externa a gran escala ha priorizado la clasificación de las escuelas, esta investigación analiza los resultados de este proceso con la red de enseñanza de la $10^{\mathrm{a}} \mathrm{ADR}$ de Caçador y la percepción de los docentes sobre sus reales efectos en la planificación. Utilizando la investigación exploratoria y documental y los enfoques cualitativos y cuantitativos, el estudio encontró que si bien los docentes conocen los resultados del ciclo de evaluación, la mayoría desconoce los descriptores y otras implicaciones subyacentes a la evaluación a gran escala.

Palabras clave: Educación básica. Evaluación. Planificación.

\section{Introdução}

crescente regulação do ensino, efetivada pelo sistema federal, desde 1990, e
a responsabilidade atribuída às escolas para solucionar grande parte de suas
próprias demandas, conforme destacado por Dourado (2007), são desafios 
estes a capacidade de compatibilizar as políticas públicas em vigência no âmbito nacional com as especificidades das instituições de ensino das diferentes regiões brasileiras, exigindo-se que promovam uma educação que atinja os índices de qualidade projetados externamente, por outro, existe também a relevância de que estimulem um ensino contextualizado, capaz de articular currículo e realidade, com o intuito de minimizar os impactos de uma avaliação externa em larga escala, sustentada pela lógica do ranqueamento, da competição e da punição.

As reformas educacionais que impulsionaram o ranqueamento como ênfase avaliativa na década de 1990 foram justificadas pelos baixos índices de aprendizagem (MELO, 1999). Essas reformas têm afetado diretamente as escolas, os gestores e docentes, que precisam, isoladamente, buscar alternativas para enfrentar tais desafios, já que a prática governamental adotada em decorrência dos resultados tem subestimado a necessidade de estimular condições que favoreçam sua melhora.

Os desafios advindos da responsabilização das escolas apresentam-se como decorrentes de uma "[...] perspectiva pedagógica individualista, dualista e fragmentária coerente com o ideário da desregulamentação, flexibilização e privatização e com o desmonte dos direitos sociais ordenados por uma perspectiva de compromisso social coletivo [...]" (FRIGOTTO; CIAVATTA, 2003, p. 93-130). Os autores destacam, ainda, que as ideologias das competências e da empregabilidade se constituem em eixos centrais dos parâmetros, das diretrizes educacionais e dos mecanismos dessa ênfase avaliativa.

Essas perspectivas impossibilitam a função da avaliação conforme defendida por Ala-Harja e Helgason (2000), quando afirmam que ela precisa ser compreendida como um processo essencial para a tomada de decisão e, nesse sentido, os resultados devem fundamentar decisões para retroalimentar o processo. Posicionamento próximo a esse já era defendido por Libâneo (2013, p. 195) ao afirmar que "A avaliação é uma tarefa complexa que não se resume à realização de provas e atribuição de notas [...]". Portanto, os processos de avaliação devem priorizar, além da coleta de dados referentes ao rendimento e à progressão, diferentes dimensões do processo educacional, estando a serviço "[...] da construção do conhecimento, da harmonia, da conciliação, da aceitação dos diferentes, tendo como premissa uma melhor qualidade de vida" (BEHRENS, 2005, p. 75).

Essa premissa passa a ser tangível especialmente quando a avaliação institucional externa é compatibilizada com a autoavaliação. Isso acontece porque a autoavaliação consiste em um "[...] exercício realizado em conjunto com outros [...]", assentado "[...] na lógica do confronto intersubjetivo e ajustado no princípio da reflexão sobre o trabalho desenvolvido para melhorar a prestação do serviço educativo" (TERRASÊCA, 2016, p. 167).

Para colaborar com esse serviço desenvolvido em municípios das mesorregiões norte e oeste catarinense, explorando os resultados do processo de avaliação externa e da criação de iniciativas de autoavaliação, esta pesquisa teve como objetivo analisar os índices 
atingidos no penúltimo processo avaliativo, efetuado em sete redes municipais, as quais estavam vinculadas, no momento deste estudo, à $10^{a}$ Agência de Desenvolvimento Regional (10 a ADR - Caçador), no estado de Santa Catarina. Além disso, a pesquisa também objetiva analisar a percepção de docentes que atuam em um dos municípios da região, especificamente sobre a utilização desses resultados nos processos de planejamento subsequentes, bem como suas perspectivas sobre a implementação da autoavaliação institucional, que surge como uma das possibilidades para superar as limitações oriundas da ênfase exclusiva no ranqueamento.

\section{Avaliação com ênfase no ranqueamento}

Dentre as várias reformas na educação brasileira ao longo da história, Aguiar (2002) faz referência à impulsionada a partir da última década do século $X X$, que se consolidou como uma das estratégias adotadas pelo Governo Federal para realizar mudanças no aparato estatal que influenciassem todas as esferas da sociedade. Em sua implantação, a reforma se comprometia com a reestruturação da máquina burocrática e, ao mesmo tempo, pretendia mobilizar a sociedade civil para colaborar com o projeto de modernização do País, estimulando uma cumplicidade nas transformações daí decorrentes.

A autora também destaca que, mesmo apontando para uma descentralização das políticas de educação, o Governo Federal ampliava, com a reforma, sua interferência nas políticas dos estados e municípios. Para isso, passou a estabelecer diversos mecanismos de controle, entre os quais as propostas relativas à avaliação do sistema educacional, desenvolvidas e implantadas pelo Instituto Nacional de Estudos e Pesquisas Educacionais (Inep), para atender o ideário de racionalidade implicado na reforma educacional.

Esse processo foi impulsionado a partir de 1995, quando o Governo Federal acatou na íntegra os resultados do Seminário de Ensino Fundamental \& Produtividade Empresarial. A iniciativa aproximou a educação da lógica da produtividade e definiu tanto o estabelecimento de um sistema de controle de qualidade, configurando, dessa forma, a avaliação institucional, como a definição de recursos para a operação eficiente e eficaz das escolas, caracterizando um movimento de correlação de forças centrado na hegemonia neoliberal (PERONI, 2003).

Foi dessa forma que a avaliação se afirmou como uma das estratégias para adequar a área educacional aos novos imperativos econômicos, que passaram a determinar as políticas públicas. Nesse contexto, a inspiração de racionalidade técnica passou a justificar as reformas apregoadas pelas políticas públicas para a educação (BAZZO, 2006).

Processos como esses posicionam os docentes como receptáculos de diretrizes governamentais e acentuam as políticas públicas como um processo formal de cumprimento de regras e normativas (MAINARDES, 2006). Em sua efetivação, “[...] tais políticas não 
são propostas, amadurecidas e refletidas a partir da realidade local, mas 'aterrizam' na realidade escolar municipal sem prévia negociação ou diálogo mediador que poderia ser gerado se houvesse efetivo regime de colaboração" (WERLE; THUM; ANDRADE, 2009, p. 20, grifos dos autores).

Ao subtrair do debate social o significado das escolhas implícitas, as iniciativas de avaliação estimulam a crença de que existe uma convergência em relação à qualidade. Essa crença vai, sorrateiramente, sendo interiorizada pelas redes de ensino e pela sociedade (SORDI, 2012). Além disso, os "[...] relatórios, elaborados para administradores, técnicos e, em geral, para os responsáveis pela definição e implementação de políticas educacionais, não costumam chegar às mãos dos professores para fins de análise, discussão e estabelecimento de linhas de ação [...]" (VIANNA, 2003, p. 45). Em decorrência disso, o autor afirma que o impacto dos resultados na tomada de decisão e no redimensionamento dos processos de ensino e de aprendizagem é reduzido.

As avaliações em larga escala, sustentadas pela ênfase economicista e tecnicista, passaram a somar uma ampla base de dados sobre o rendimento de estudantes de diferentes etapas formativas, e sua utilização tem priorizado o ranqueamento de resultados, distanciando-se tanto da qualidade como do estabelecimento de prioridades a partir dos resultados obtidos (ABICALIL, 2002). Tais resultados, incorporados como indicadores de alta relevância para a confirmação do sucesso, ou não, de políticas educacionais e de práticas escolares, tendem a "[...] induzir administradores a colocarem em suas agendas o compromisso com a melhoria do rendimento escolar dos alunos, além de fluxo escolar, tradicionalmente considerado como referência de qualidade" (MARTINS; SOUSA, 2012, p. 23). Ou seja, essa reação reducionista limita a abrangência das dimensões avaliadas, desconsiderando a complexidade do processo educativo.

Sousa (2014) trata das diferentes intencionalidades nesse processo e ressalta que sempre existem tendências influenciando no delineamento das propostas avaliativas e no uso de seus resultados. Essas tendências se manifestam de acordo com os parâmetros estabelecidos, com seus objetivos e suas metas, bem como com os atores que participam do processo, sendo possível, desse contexto, "[...] inferir algumas finalidades, entre as quais se situam: certificação; comparação; seleção/classificação/progressão; diagnóstico; controle" (ABICALIL, 2002, p. 267).

Na seleção dos processos avaliativos, estão presentes "[...] posições, crenças, visões de mundo e práticas sociais de quem os concebe, mas emergem da perspectiva filosófica, social e política de quem faz o julgamento e dela são expressão”. Dessa forma, “[...] os enfoques e critérios assumidos em um processo avaliativo revelam as opções axiológicas dos que dele participam" (SOUSA, 1997, p. 127).

Ao explorar as características das proposições e evidências de usos que vêm sendo feitos de seus resultados, Sousa (2014) reforça questões implícitas em um processo avaliativo, afirmando que existem vários desdobramentos decorrentes das avaliações em 
larga escala. A autora também considera que a destinação de recursos diferenciados para as escolas, como meio de premiação, reforça a competição no interior das redes de ensino como estratégia para induzir melhores resultados. Essa competição é fortalecida, segundo Sousa, quando se responsabilizam as escolas e, especificamente, seus docentes pelos resultados da avaliação, associando-os ao recebimento ou não de incentivos, condição que colabora para fomentar a ideia de que competição gera qualidade.

É nesse contexto que o conceito de avaliação vinculado à competitividade entre instituições e docentes é reforçado, e o conceito de qualidade passa a se constituir em um "[...] produto da própria competição pela construção de uma coleção de indicadores legitimados socialmente pelos atores" (FREITAS, 2004, p. 149). Essa ênfase reafirma que políticas educacionais elaboradas e desenvolvidas sob a égide da classificação e seleção, incorporando a exclusão como consequência inerente aos seus resultados, restringem o direito de todos à educação (SOUSA, 2009). Em decorrência disso, a “[...] avaliação se firma cada vez mais como elemento da regulação e da administração gerencial e competitiva do 'Estado-avaliador' no Brasil, com uma história de mais de vinte anos" (COELHO, 2008, p. 231).

Por outro lado, Abicalil (2002) lembra que a avaliação deveria ser posta na perspectiva da valorização, atendendo o previsto na Lei de Diretrizes e Bases da Educação Brasileira (LDBEN 9394/96). Para tanto, ela deve ultrapassar a relação entre proficiência dos estudantes e premiação, relação esta que incide em uma dinâmica em que menos aprendizagem justificaria menos investimento, legitimando a falta de qualidade e a promoção da desigualdade como propriedades da natureza do processo escolar. Existe, portanto, uma emergência de promover reflexões "[...] sobre a relação entre a centralidade que a avaliação da educação básica tem recebido na política pública e as tendências na construção científica de seus processos e resultados, bem como sobre suas implicações na gestão escolar e no trabalho dos profissionais da escola" (COELHO, 2008, p. 231). Ou seja, a avaliação em larga escala não pode permanecer reduzida à aferição do desempenho cognitivo, realizada exclusivamente pelo método quantitativo (ARMSTRONG, 2008).

\section{Metodologia de pesquisa}

Tendo como intenção contribuir para que os municípios envolvidos na pesquisa possam buscar alternativas que superem a ênfase da avaliação no ranqueamento, este estudo analisa os resultados desse processo junto às redes de ensino da $10^{\underline{a}} \mathrm{ADR}$ de Caçador e também a percepção de docentes sobre os seus reais efeitos nos planejamentos, priorizando o uso da pesquisa documental e da pesquisa exploratória. A primeira destina-se à análise de documentos (MARCONI; LAKATOS, 2010) e possibilitou o acesso ao relatório disponibilizado pelo Ministério da Educação (BRASIL, 2016), no qual constam as metas 
previstas e as alcançadas pelos municípios brasileiros, incluindo os que integravam a $10^{\underline{a}} \mathrm{ADR}$ - Caçador. A pesquisa exploratória, por sua vez, é utilizada para proporcionar uma visão geral, de tipo aproximativo, acerca de determinado fato (GIL, 2006), favorecendo a coleta de dados referentes à percepção dos docentes envolvidos na pesquisa.

Quanto à abordagem, optou-se pela qualitativa e pela quantitativa. A primeira difere da segunda na medida em que não "[...] pretende numerar ou medir unidades ou categorias homogêneas" (RICHARDSON, 2007, p. 79).

Para a coleta de dados, utilizou-se um questionário, elaborado a partir da análise dos Indicadores da Qualidade na Educação (Indique) ${ }^{1}$, que envolvem as seguintes dimensões: ambiente educativo, prática pedagógica e avaliação, aprendizagem da leitura e da escrita, gestão escolar democrática, formação e condições de trabalho dos profissionais da escola, ambiente físico escolar e acesso e permanência dos alunos na escola. Esses indicadores são compreendidos como sinais de qualidade, e os resultados apontados são frutos de discussões na comunidade escolar, a partir da análise que esta realiza sobre situações, atitudes e práticas que ocorrem ou não na escola (RIBEIRO; GUSMÃO, 2010).

O questionário aplicado nesta pesquisa manteve como base os quatro aspectos determinantes do Indique (avaliação, disseminação dos resultados alcançados, formação/ planejamento e intervenção), que passaram a ser considerados como dimensões do novo instrumento. A partir dessas dimensões, foram elaboradas onze questões, priorizando a coleta de dados relativos ao último ciclo avaliativo do Ideb de 2015 e, também, as possibilidades para o desenvolvimento de um processo de autoavaliação decorrente.

Sua aplicação envolveu uma população de 106 docentes, sendo selecionada uma amostra de 37 profissionais em função da disponibilidade de participar do processo. Aos sujeitos participantes da pesquisa, considerando os princípios éticos implicados em sua realização, foi entregue o Termo de Consentimento Livre e Esclarecido (TCLE) como meio de assegurar-lhes tanto as condições de sigilo necessárias quanto a possibilidade de evadirem do estudo, caso desejassem.

Quanto ao perfil, foram coletados dados referentes à idade, formação, atuação e ao regime de contratação. Dos 37 docentes, 54\% têm entre 31 e 40 anos, 27\% entre 41 e 50 anos e 19\% entre 21 e 30 anos. Em relação à formação, 60\% têm especialização, 32\% graduação, $5 \%$ graduação em andamento e $3 \%$ especialização em andamento. Dos profissionais com graduação completa, $48 \%$ têm graduação em pedagogia e os demais em áreas específicas, entre as quais língua portuguesa e matemática. Destaca-se também que 35\% atuam no ensino fundamental II, 27\% no ensino fundamental I, 22\% atuam na educação infantil, enquanto $16 \%$ atuam tanto na educação infantil como no ensino fundamental I. Em relação ao regime de trabalho, 51\% têm contrato de substitutos e $49 \%$ são efetivos. 


\section{Resultados e discussão}

Considerando o objetivo desta pesquisa, foram analisados, em sua primeira etapa, os resultados do IDEB dos sete municípios implicados no estudo: Caçador, Calmon, Lebon Régis, Macieira, Matos Costa, Rio das Antas e Timbó Grande. Destaca-se que a população desses municípios é formada por 103.962 habitantes (IBGE, 2010), sendo Caçador o mais populoso, com 70.762 habitantes, seguido de Lebon Régis, com 11.838 habitantes.

Por meio da análise documental, observou-se que a meta do Ideb projetada para o ano de 2015 foi alcançada nos anos iniciais do ensino fundamental das sete redes municipais de ensino, enquanto o índice não foi alcançado nos anos finais em nenhum dos três municípios com média prevista, conforme registrado na Tabela $1^{2}$. Destaca-se que quatro municípios não realizaram a avaliação dos anos finais porque não possuíam o número de estudantes requisitado no processo.

\section{Tabela 1 - Índices da educação básica das redes municipais de ensino da $10^{\mathrm{a}}$ ADR - Caçador - Ano 2015}

\begin{tabular}{l|c|c|c|c}
\hline \multirow{2}{*}{ RME } & \multicolumn{2}{c|}{ Anos Iniciais } & \multicolumn{2}{c}{ Anos Finais } \\
\cline { 2 - 5 } & $\begin{array}{c}\text { Meta } \\
\text { Projetada }\end{array}$ & $\begin{array}{c}\text { Índice } \\
\text { Observado }\end{array}$ & $\begin{array}{c}\text { Meta } \\
\text { Projetada }\end{array}$ & $\begin{array}{c}\text { Índice } \\
\text { Observado }\end{array}$ \\
\hline Caçador & 5,2 & 5,5 & 4,4 & 4,1 \\
\hline Lebon Régis & 4,4 & 4,7 & 4,8 & 3,7 \\
\hline Timbó Grande & 5,4 & 5,7 & 4,9 & 4,3 \\
\hline Rio das Antas & 5,6 & 6,7 & -- & 5,4 \\
\hline Calmon & 4,7 & 5,4 & -- & - \\
\hline Macieira & 5,6 & 6,4 & -- & - \\
\hline Matos Costa & 5,2 & 5,3 & -- & - \\
\hline
\end{tabular}

Fonte: Brasil (2016).

A classificação situa a Rede Municipal de Ensino de Rio das Antas com o índice mais elevado nos anos iniciais do ensino fundamental, obtendo mais de um ponto acima da média projetada, seguida por Macieira e Timbó Grande. Já nos anos finais, a Rede Municipal de Ensino de Rio das Antas também obteve o índice mais elevado, seguida de Timbó Grande e Caçador; entretanto, destaca-se que nenhum dos municípios atingiu a meta projetada.

Considerando que a média projetada para os sistemas municipais em 2015 foi de 4,8 nos anos iniciais do ensino fundamental, o índice obtido por seis municípios pode ser considerado relevante. Ainda assim, não se elimina a preocupação com os índices 
obtidos na região, especialmente nos anos finais, já que, para 2021, espera-se que as redes municipais de ensino obtenham, minimamente, a média 5,1.

Com base nesses resultados, a segunda etapa da pesquisa coletou dados atinentes à percepção de docentes vinculados a uma das redes municipais de ensino. A iniciativa teve como propósito buscar subsídios para intervir nos próximos anos, especialmente porque, segundo Depresbiteris (2001, p. 141), é relevante o alinhamento da avaliação externa à interna. Nesse processo, observa-se que as iniciativas podem ser emancipadoras ou servir à intensificação das desigualdades educacionais e sociais, pois tanto os fins e meios empregados como o uso '[...] de seus resultados são reveladores do real significado que assumem no processo educacional" (SOUSA; ARCAS, 2010, p. 187).

\section{Acesso aos resultados do Ideb}

Consultados sobre o Ideb 2015, 73\% dos docentes participantes da pesquisa informaram que tiveram acesso ao resultado e $27 \%$, que não. No caso dos que tiveram acesso, $43,2 \%$ afirmaram que isso se deu por meio da escola em que atuam, 40,5\% acessaram os resultados via internet, 10,8\% pela Secretaria Municipal de Educação (SME) e 5,4\% durante o Curso Nacional pela Alfabetização na Idade Certa (Pnaic).

Considerando que parte dos docentes atua exclusivamente na educação infantil e que somente uma escola do município participou do processo avaliativo de 2015, a forma de acesso aos resultados ficou pulverizada. Em um processo de autoavaliação e de efetiva intervenção relacionada aos resultados, a tendência é que a Secretaria Municipal de Educação e as escolas acentuem a difusão dos resultados, estimulando que a avaliação e o planejamento participativo colaborem para melhorar os processos de ensino e de aprendizagem, conforme defendem Ribeiro e Gusmão (2010).

\section{Formação e conhecimento da Prova Brasil}

Quanto à formação sobre o processo de avaliação externa da educação básica, 59\% afirmaram que nunca haviam participado e $41 \%$, que sim. Os resultados foram idênticos quando foram questionados se a escola em que atuam oferece alguma formação em relação ao referido processo avaliativo.

Apesar de um percentual relativo ter participado de alguma iniciativa e parte das escolas estar realizando alguma atividade formativa, $81,1 \%$ desconheciam os descritores da Prova Brasil. Ainda que tenham sido ofertadas atividades para se discutir o processo, o desconhecimento dos descritores indica a falta de uma política formativa do Governo Federal, que lança a avaliação em larga escala sem dinamizar condições para que as 
escolas elaborem seus planejamentos, usando como base o processo avaliativo precedente e os resultados obtidos. Essa falta de formação impede a superação da avaliação exclusivamente comparativa, classificatória e de controle, destacada por Souza (2014); também reafirma as conclusões do estudo realizado por Werle, Thum e Andrade (2009), de que as avaliações externas de larga escala da educação básica não se articulam, por meio de espaços de colaboração e diálogo, entre as instâncias do Estado.

Apesar disso, Horta Neto (2013) reforça que tanto estados como municípios vêm, gradualmente, acolhendo resultados da avaliação externa como referência para iniciativas de gestão e para a criação de propostas próprias de avaliação, considerando o modelo estabelecido nacionalmente. Nesta questão reside uma das preocupações que deu origem a esta pesquisa: limitar a avaliação interna aos moldes do processo de avaliação externa reafirma um modelo de competição e de individualismo.

\section{Intervenções decorrentes da avaliação externa}

Em relação às intervenções realizadas como decorrência do processo de avaliação externa, 62,2\% registraram que desconheciam alguma iniciativa de destaque. Contudo, $32,4 \%$ fizeram referência ao simulado e 5,4\% dos sujeitos pesquisados apontaram a inclusão de questões em avaliações rotineiras, elaboradas a partir das formações.

Ainda que o desconhecimento seja justificado pelo fato de que parte dos docentes não atua na escola em que participou do último processo avaliativo externo, os dados apontam para a necessidade de ampliar a tomada de decisão coletiva em relação aos diagnósticos realizados, por serem representativos do município. Nesse sentido, destaca-se a importância de organizar um processo de autoavaliação que possa ampliar as dimensões consideradas na avaliação externa e favorecer a autoavaliação institucional da rede pesquisada.

\section{Perspectivas sobre o processo de autoavaliação}

Reconhecendo-se a importância de um processo avaliativo mais amplo e que implique dimensões que vão além da cognitiva, coletaram-se dados referentes à autoavaliação institucional, incluindo sugestões para sua realização, como segmentos a serem envolvidos, dimensões a serem avaliadas e documentos que poderiam ser reformulados com base nos resultados. Essa iniciativa tem relação com a afirmação de Vieira e Côco (2015, p. 131), de que se deve reconhecer a "[...] a comunidade escolar como uma unidade que pode construir um referencial de qualidade para a instituição da qual faz parte [...]". 
Entre as principais sugestões para a realização da autoavaliação, foram destacadas: a oferta de momentos de formação, incluindo oficinas e fóruns, além de outros espaços para a discussão do processo envolvendo a comunidade interna e externa; a definição de técnicas e a elaboração de instrumentos de pesquisa para serem aplicados na escola e na comunidade; o estabelecimento de uma rotina avaliativa, incluindo a realização de simulados para avaliar o rendimento, mas também outras pesquisas internas e externas que considerem outras dimensões do processo; e, ainda, a deliberação sobre formas de análise dos resultados e sua difusão.

Em relação à participação de diferentes segmentos na autoavaliação, os docentes acentuaram a inclusão da comunidade escolar interna e externa, representada por estudantes, pais, docentes, gestores e profissionais técnicos, bem como de representantes de conselhos deliberativos, da Secretaria Municipal de Educação e de outras instâncias implicadas nas políticas educacionais do município, entre as quais os poderes Legislativo e Executivo. Essas sugestões convergem com o que aponta o Indique e também com o que foi destacado por Ribeiro e Gusmão (2010), ao defenderem que um processo de autoavaliação institucional deve envolver gestores, docentes, estudantes, profissionais-técnicos, pais, representantes da comunidade, conselhos e instituições que tenham relação com a escola.

Quanto às dimensões determinantes na coleta de dados, os docentes indicaram a infraestrutura, a gestão, a formação continuada, o desempenho profissional, o planejamento, a participação da comunidade interna e externa, os materiais didáticos, os conteúdos curriculares, o perfil socioeconômico dos estudantes, a relação entre escola e comunidade, as práticas pedagógicas, entre outras.

Ao selecionar os documentos que poderiam ser redimensionados a partir da autoavaliação, os docentes destacaram o Plano Municipal de Educação(PME), o projeto político pedagógico (PPP) de cada instituição, o planejamento anual, os projetos de ensino e aprendizagem e os planos de aula. A indicação desses documentos converge com as preocupações de Crochoska (2013) sobre a avaliação envolvendo as instituições de ensino de estimularem a reflexão sobre a gestão e a necessidade de reformulação de políticas públicas educacionais, bem como de fornecer dados que colaborem com o PPP e seus desdobramentos.

\section{Considerações finais}

A relevância da avaliação da educação reside no potencial que ela oferece para se tomar decisões que colaborem para melhorar os processos de ensino e de aprendizagem. Essa perspectiva opõe-se à concepção implícita nas reformas governamentais impulsionadas no contexto brasileiro no decorrer da década de 1990, que funcionavam sob a égide da produtividade. 
De acordo com a lógica das reformas, o uso dos resultados tem como principal finalidade a definição de políticas de responsabilização. Assim, escolas e docentes carecem de condições (como formação para analisar e interpretar a realidade diagnosticada, bem como para agir a partir dela) para melhorar, além do desempenho, outros aspectos inerentes ao processo educacional.

No contexto desta pesquisa, os resultados indicam que, apesar de iniciativas realizadas em decorrência do acesso aos resultados do penúltimo ciclo avaliativo, o desconhecimento em relação aos descritores da Prova Brasil confirma a fragilidade do processo, ou seja, os docentes, de uma forma geral, sabem que serão avaliados e sabem os índices obtidos, mas desconhecem as dimensões a partir das quais as questões da prova são estruturadas.

Assim, a autoavaliação se apresenta como um - senão o mais relevante e significativo - processo para fazer frente às contradições que resultam das avaliações externas em grande escala. Sendo ela compreendida como um "[...] processo contínuo de interpelação das práticas de educação e de ensino [...]" que estimula "[...] o confronto entre os diversos estilos de docência, de relacionamento interpessoal, de liderança, entre muitos outros aspetos [...]" (TERRASÊCA, 2016, p. 166). Portanto, a autoavaliação ultrapassa a dimensão cognitiva para incorporar outras demandas do processo educacional. A partir dessa compreensão, a autora reforça a necessidade de se reconhecer que ainda há um intenso e profundo trabalho a ser desenvolvido.

A indicação de possibilidades para implantar um processo de autoavaliação expressa o sentido de responsabilidade que permeou a prática dos sujeitos aqui pesquisados. Este estudo indica, portanto, a necessidade de investimento na formação, para que os profissionais que atuam nas escolas possam: conhecer como se estruturam os instrumentos avaliativos, analisar os resultados e tomar decisões para melhorar os processos de ensino e de aprendizagem. Além disso, compete ao Governo Federal ampliar e aprofundar as dimensões avaliadas, além de superar a lógica da punição e, dessa forma, oferecer condições para se melhorar a qualidade.

Esse processo tende a tornar-se ainda mais significativo se as instituições adotarem processos de autoavaliação. Para tanto, são válidas as sugestões apontadas pelos sujeitos da pesquisa em relação a possíveis segmentos a serem envolvidos, dimensões a serem avaliadas e documentos que poderiam ser reformulados a partir dos resultados.

Existem, portanto, por parte dos pesquisados, preocupações não consideradas no processo de avaliação externo. Nesse sentido, o estudo revela que ainda se observa uma grande lacuna na avaliação da educação básica. A eliminação dessa lacuna depende do compromisso das escolas e dos profissionais que nelas atuam, mas também do poder público, que traça as políticas educacionais para o País. 


\section{Notas}

1 O Indique é um instrumento de autoavaliação voltado para escolas de ensino fundamental, cujo objetivo é envolver a comunidade escolar em processos de promoção da qualidade na educação. Ele é resultado de um trabalho coordenado por organizações como o Fundo das Nações Unidas para a Infância (Unicef) e o Instituto Nacional de Estudos e Pesquisa Educacionais (Inep) (RIBEIRO; GUSMÃO, 2010).

2 A opção da análise dos dados do referido ano se justifica por ampliar possibilidades para avaliar as iniciativas priorizadas, a partir de então, para melhorar os resultados.

\section{Referências}

ABICALIL, Carlos Augusto. Sistema Nacional de Educação Básica: Nó da avaliação? Educação e Sociedade, CEDES: Campinas, v. 23, n. 80, p. 253-274, set. 2002.

AGUIAR, Márcia Ângela da S. Conselho Nacional de Secretários de Educação na Reforma Educacional do Governo FHC. Educação e Sociedade, CEDES: Campinas, v. 23, n. 80, p.72-89, 2002.

ALA-HARJA, Marjukka; HELGASON, Sigurdur. Em direção às melhores práticas de avaliação. Revista do Serviço Público, Brasília, v. 51, n. 4, p. 5-59, out./dez. 2000.

ARMSTRONG, Thomas. As melhores escolas: a prática educacional orientada para o desenvolvimento humano. Porto Alegre: Artmed, 2008.

BAZZO, Vera Lúcia. As consequências do processo de reestruturação do Estado brasileiro sobre a formação dos professores da Educação Básica. In: PERONI, Vera Maria Vidal et al. (Org.). Dilemas da educação brasileira em tempos de globalização neoliberal: entre o público e o privado. Porto Alegre: Editora UFGRS, 2006. p. 18-32.

BEHRENS, Marilda Aparecida. O Paradigma emergente e a prática pedagógica. 4. ed. Curitiba: Editora Universitária Champagnat. 2005.

BRASIL. IDEB: apresentação. Brasília: MEC, 2016. Disponível em: <http://portal.mec.gov.br/secretariade-educacao-basica/programas-e-acoes?id=180>. Acesso em: $1^{\underline{0}}$ jun. 2017.

COELHO, Maria Inês de Matos. Vinte anos de avaliação da educação básica no Brasil: aprendizagens e desafios. Ensaio: Avaliação e Políticas Públicas em Educação, Rio de Janeiro, v. 16, n. 59, p. 229-258, abr./ jun. 2008.

CROCHOSKA, Marcia Andreia. As contribuições da autoavaliação institucional para a escola de Educação Básica. Petrópolis: Vozes, 2013.

DEPRESBITERIS, Léa. A avaliação na Educação Básica: ampliando a discussão. Estudos em Avaliação Educacional, São Paulo, n. 24, jul./dez. 2001.

DOURADO, Luiz Fernandes. Políticas e gestão da educação básica no Brasil: limites e perspectivas. Educação \& Sociedade, CEDES: Campinas, v. 28, n. 100, p. 921-946, 2007. 
FREITAS, Luiz Carlos. A Avaliação e as reformas dos anos de 1990: novas formas de exclusão, velhas formas de subordinação. Educação e Sociedade, CEDES: Campinas, v. 25, n. 86, p. 131-170, abr. 2004.

FRIGOTTO, Gaudêncio; CIAVATTA, Maria. Educação Básica no Brasil na década de 1990: subordinação ativa e consentida à lógica do mercado. Educação e Sociedade, CEDES:Campinas, v. 24, n. 82, p. 93-130, abr. 2003.

GIL, Antonio Carlos. Métodos e técnicas de pesquisa social. 5. ed. São Paulo: Atlas: 2006.

HORTA NETO, João Luiz. As avaliações externas e seis efeitos sobre as políticas educacionais: uma análise comparada entre a União e os estados de Minas Gerais e São Paulo. 2013. 358 p. Tese (Doutorado em Política Social) - Instituto de Ciências Humanas - Universidade de Brasília, Brasília, 2013.

IBGE. Informações sobre os municípios brasileiros. Rio de Janeiro: IBGE, 2010. Disponível em: <http:// cidades.ibge.gov.br/xtras/home.php>. Acesso em: 20 maio 2016.

LIBÂNEO, José Carlos. Didática. 2. ed. São Paulo: Cortez, 2013.

MAINARDES, Jeferson. Abordagem do ciclo de políticas: uma contribuição para a análise de políticas educacionais. Educação e Sociedade, CEDES: Campinas, v. 27, n. 4, p. 47-94, 2006.

MARCONI, Marina de Andrade; LAKATOS, Eva Maria. Fundamentos de metodologia científica. 7. ed. São Paulo: Atlas, 2010.

MARTINS, Ângela Maria; SOUSA, Sandra Zákia. A produção científica sobre avaliação educacional e gestão de sistemas e de escolas: o campo da questão entre 2000 a 2008. Ensaio: Avaliação e Políticas Públicas em Educação, Rio de Janeiro, v. 20, p. 9-26, 2012.

MELO, Marcus André. Estado, governo e políticas públicas. In: MICELI, S. (Org.). O que ler na ciência social brasileira (1970-1995), v. 3. São Paulo: Sumaré, 1999. p. 59-100.

PERONI, Vera Maria Vidal. Política educacional e papel do Estado: no Brasil dos anos 1990. São Paulo: Xamã, 2003.

RIBEIRO, Vanda Mendes; GUSMÃO, Joana Borges Buarque de. Uma leitura dos usos dos indicadores da qualidade na educação. Cadernos de Pesquisa, FCC: São Paulo, v. 40, n. 141, p. 823-847, 2010.

RICHARDSON, Roberto Jarry. Pesquisa social: métodos e técnicas. 3. ed. São Paulo: Atlas, 2007.

SOUSA, Sandra Zákia. Avaliação escolar e democratização: o direito de errar. In: AQUINO, Julio Groppa. (Coord.). Erro e fracasso na escola: alternativas teóricas e práticas. São Paulo: Summus, 1997. p. 125-140.

SOUSA, Sandra Zákia. Avaliação e gestão da educação básica. In: DOURADO, Luiz Fernandes. Políticas e gestão da educação no Brasil: novos marcos regulatórios. São Paulo: Xamã, 2009. p. 31-45.

SOUSA, Sandra Zákia. Concepções de qualidade da educação básica forjadas por meio de avaliações em larga escala. Avaliação, Campinas; Sorocaba, v. 19, n. 2, p. 407-420, jul. 2014.

SOUSA, Sandra Zákia; ARCAS, Paulo Henrique. Implicações da Avaliação em Larga Escala no Currículo: revelações das escolas estaduais de São Paulo: Educação: Teoria e Prática. São Paulo, v. 20, n. 35, p.181199, jul./dez. 2010.

SORDI, Mara Regina Lemes de. Possibilidades e limites da avaliação em larga escala na construção da qualidade da escola pública. Série-Estudos - Periódico do Programa de Pós-Graduação em Educação da UCDB, Campo Grande, n. 33, p. 39-53, jan./jul. 2012.

TERRASÊCA, Manuela. Autoavaliação, avaliação Externa... afinal para que serve a avaliação das escolas? Cadernos Cedes, Campinas, v. 36, n. 99, p. 155-174, maio/ago. 2016. 
VIANNA, Heraldo Marelim. Avaliações nacionais em larga escala: análises e propostas. Estudos em Avaliação Educacional, São Paulo, n. 27, p. 41-76, jan.jjun. 2003.

VIEIRA, Nilceia; CÔCO, Valdete. Avaliação e qualidade: diferentes percursos na Educação Básica. Roteiro, Joaçaba, v. 40, n. 1, p. 127-148, jan./jun. 2015.

WERLE, Flávia Obino Corrêa; THUM, Adriane Brill; ANDRADE, Alenis Cleusa de. Processo nacional de avaliação do rendimento escolar: tema esquecido entre os Sistemas Municipais de Ensino. Ensaio: Avaliação e Políticas Públicas em Educação, Rio de Janeiro, v. 17, n. 64, p. 397-420, jul./set. 2009. 